\title{
V.A.I. Reality. A Holistic Approach for Industrial Heritage Enhancement
}

\author{
Assunta Pelliccio \\ Marco Saccucci
}

Abstract

The post-industrial heritage, characterized by heterogeneous, tangible and intangible factors, requires digital tools and a holistic approach to undertake the most appropriate enhancement process. Current virtual realities $(\mathrm{V} r, \mathrm{Ar}, \mathrm{Ir})$ allow the modeling of physical environments and the management and virtualization of a large and varied amount of data, thus helping to better understand the complexity of the real phenomenon. The paper proposes a method, named D.V.M.R. (acronym for Design, Virtualization, Modeling, Reproduction), which in four temporally consequential phases builds a tool capable of providing territorial, environmental, architectural and historical information of a case study. The method was applied for the design of a reuse of the brick factory, known as ex Sieci and located in Scauri in southern Lazio, owned by the Municipality of Minturno. The factory, which looks like a majestic cathedral on the sea, had in the past and still has a significant centrality in the social life of the local inhabitants.

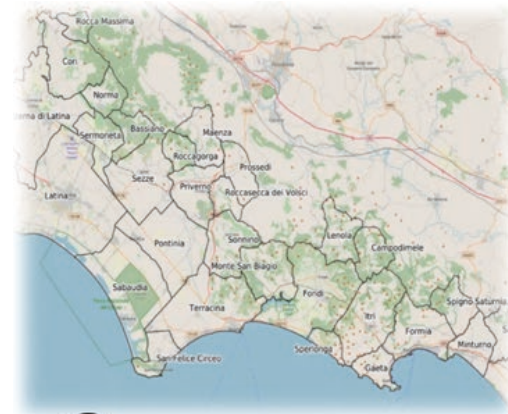

D GIS models
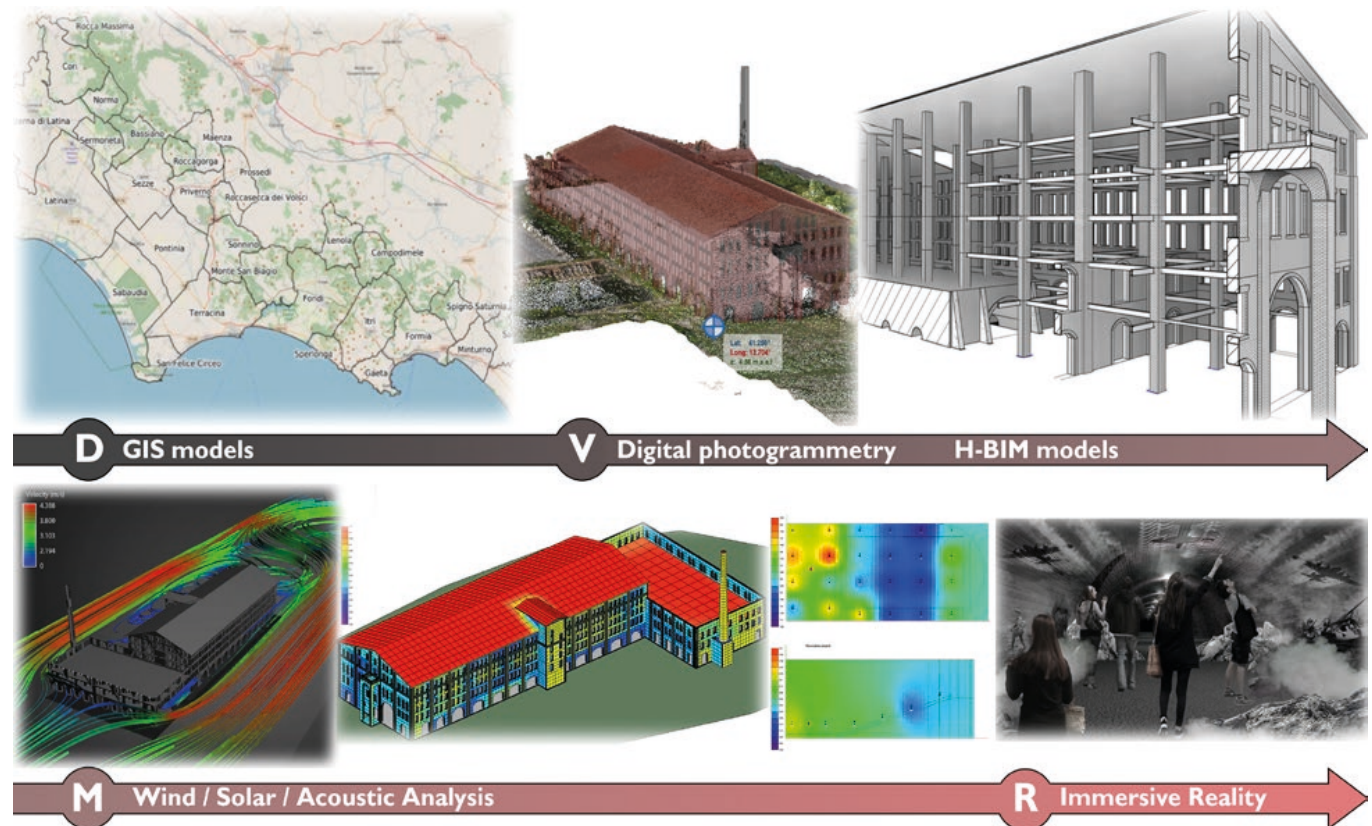


\section{Introduction}

The European Union is increasingly convinced that cultural heritage can stimulate the sustainable development of nations in terms of liveability of the environment, social cohesion, well-being, creativity and employment. This statement is even more significant in the case of post-industrial heritage, characterized by factories, chimneys and clusters of volumes necessary for industrial production, which has shaped the skyline of many cities and marked the culture of many communities. In the past, factories have attracted families and created a modus vivendi, made up of social and religious sharing, customs and traditions, generating their own genius loci. In the industrial landscape, the factory is the most important landmark, the visual and symbolic attraction of the recognizability of a community and therefore of belonging to the place. Today, however, the material and intangible cultural heritage of disused industries, consisting of both architecture but also religious and secular traditions, idioms, anecdotes still alive in the population, appears shaped by architectural skeletons that usually occupy vast urban and peri-urban areas. Sometimes these sites are highly polluting, negatively impacting the environmental sustainability indices (ESI). The current situation requires a very complex process of enhancing disused industries which must be based on urban redevelopment interventions capable of restoring both the tangible historical value, in terms of architecture, but above all the cultural, social and economic value of post industrialized communities. Today, digital technologies are of great help to this end, due to their ability in modeling cultural heritage as a complex digital asset ensuring its understanding, consultation from different points of view and to the stakeholders.

Furthermore, the combination of virtual reality (VR), augmented (AR) and immersive (IR) based on a holistic approach is the most suitable procedure for enhancing brownfields. In fact, on the one hand, virtual technologies help paradigmatically in the reading and interpretation of heterogeneous territorial and historical data, the state of conservation and

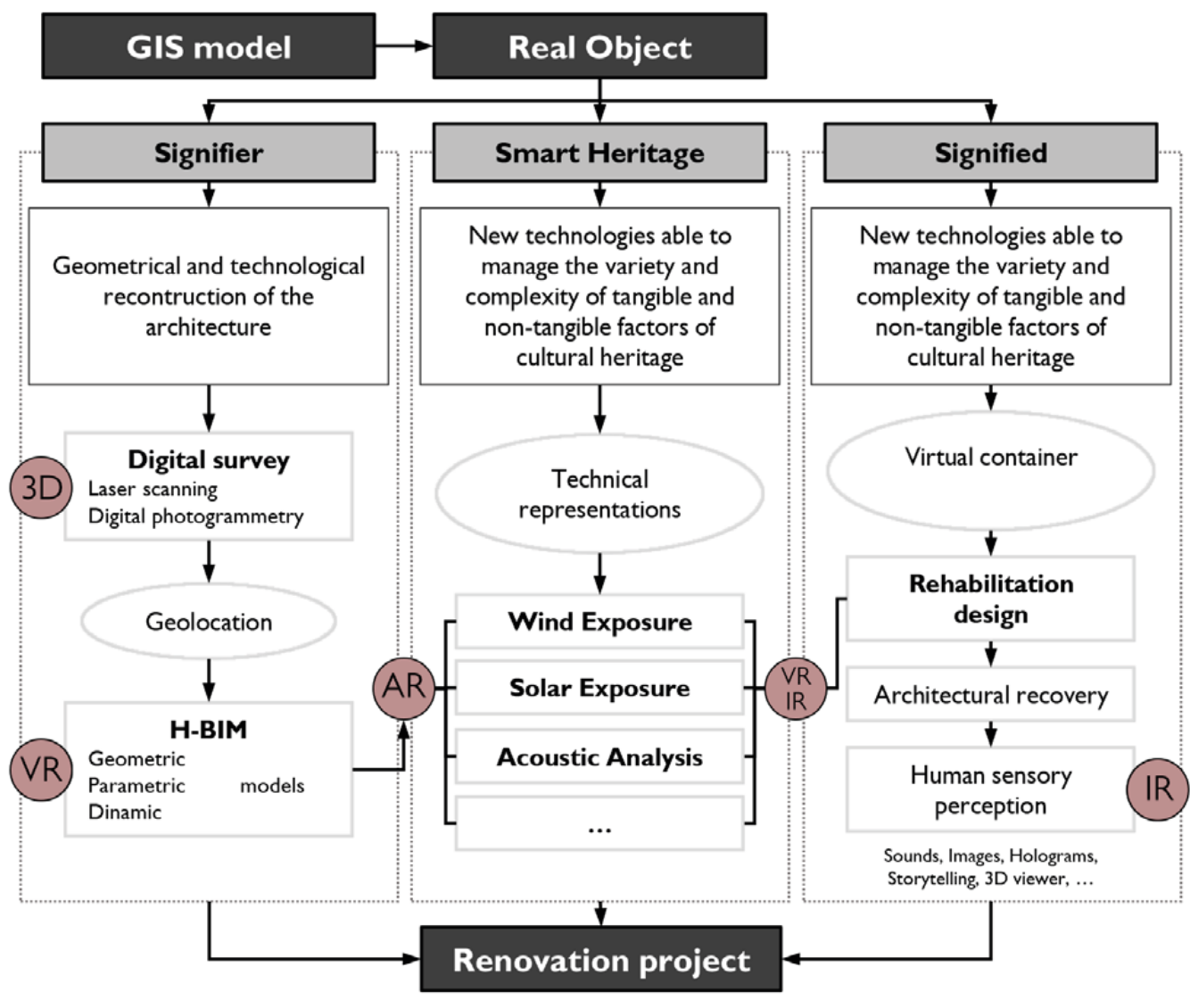


usability of the material and immaterial value of the asset. On the other hand, the holistic approach allows to have a complete overview of the phenomenon. This paper applies the new graphic language, based on the use of the informative, interactive and immersive digital model, defined as an 'smart model', combined with a holistic approach in the acquisition and management of heterogeneous data with the aim of defining the best practice in the enhancement of abandoned industrial places. To this end, the brick factory, called ex Sieci and located on the seafront of Scauri (southern Latium), was chosen as a case study.

\section{D.V.M.R. Method: the Holistic Approach in VR-AR-IR Modelling of Cultural Heritage}

Since their origins, factories have developed their own inherently holistic graphic language. The design of the factories, in fact, required the representation of both the 'architecture of space', in terms of the permanence of man and his needs, and the 'architectural space', responsible for housing the machines and their functional systems. Today as yesterday, the reuse of abandoned industrial sites, which sometimes cover several hectares of urban surface, need a new graphic language capable of visualizing, or rather virtualizing, the dimensionality and multiplicity of sites markers such as the territorial, historical and architectural factors. Nowadays virtual modeling, understood as VR, AR, IR, can dynamically and interactively manage large and heterogeneous datasets that are the informative, parametric and interactive structure of smart models. Such a complex data structure, ranging from spatial data to the smallest technological detail of the factory, must obviously also deal with the management of the relationship between each component and the functional sum of all the parts, thus following a holistic approach. In this perspective, the method proposed in the paper is able to virtualize the real object (referent) and the complex dataset associated with it, according to a holistic approach (fig. I). The method has four temporally consequential steps, described below:

I. The Design (D) of a geographical information model, GIS, which returns the environmental and territorial context of the site under study as well as the consistency of the phenomenon of abandoned industrial sites (polluting/non-polluting, recovered/abandoned, public/ private, etc.).

2.The Virtualization ( $V$ ) (signifier) of the real object (referent), obtained thanks to 3D digital surveys (laser scanning and digital photogrammetry). The point clouds exported thanks to geolocation in parametric software $(H-B \mid M)$, become the semantic structures of the informative models. In fact numerical, material, technological and historical data are associated with each graphic object, according to the most appropriate ontological model.

3.The Modelling (M) of intangible environmental phenomena (smart service). Thanks to IFC technology, the $\mathrm{H}$-BIM model can be exported to other software capable of simulating for example the wind and solar exposure or acoustic analysis.

4. The Reproduction (R) of the intangible cultural value of the site (signified). $\mathrm{H}-\mathrm{BIM}$ is a fundamental support for the immersive reality model because it is the box in which complete sensory experiences materialize through the reproduction of sounds, holograms, etc., thus helping people to be more aware of the cultural value of the site. IR also plays a key role in the decision-making process related to a post-industrial site rehabilitation project.

The D.V.M.R. uses GIS and BIM as VR models as they produce realistic 3D models within which it is possible to virtually navigate thus aiding the analysis of the entire real phenomenon. Furthermore, in DVMR, the VR models (GIS and BIM) become physical prototypes to be used in software for simulation and calculation of immaterial environmental phenomena, which for this reason can be defined as Augmented Reality (AR). This type of simulation is particularly important for analyzing and evaluating degradation phenomena on the facades of historic buildings and the design of functionality, through new and more suitable destinations in use. Similarly, in DVMR the VR models ( $H-B I M)$, are the box within which the immersive reality (IR), which ranges from entertainment, education, promotion and accessibility for people with disabilities, helps the perception of the intangible value of the asset. The D.V.M.R described above was applied in the enhancement process of an important abandoned industrial site in southern Lazio. 


\section{Case Study: Abandoned Brick Factory in Scauri}

The brick factory, called ex Seci, located in Scauri in southern Lazio, was born on a small pre-existing industrial settlement, as a branch of the Albizi furnace in Remole di Pontessieve (Florence) located on the Sieci stream from which it takes its name. The factory is part of a very delicate landscape both for its natural features and the numerous archaeological and historical evidence present in the area. The main elements are the coast called 'Riviera di Ulisse', the archaeological area of the ancient Roman town called Minturnae, the Via Appia and the mouth of the river Liri (Garigliano) on the border between Lazio and Campania Felix. The plant covered an area of 5 hectares with about 50,000 cubic meters of buildings and was connected to the sea by a destroyed wooden walkway, which facilitated the loading and unloading of products, marketed by sea. The main body of the factory, one of the few remaining, is spread over three floors above ground and rests on a base defined by a series of round arches. The building has a clear neoclassical style characterized by empty/solid rhythmic sequences, further marked by a series of pilasters which define regular modules and shape all the facades. Each floor has, between the piasters, three openings (windows) separated from each other by masonry completely covered in brick. On the ground floor there are two Hoffman ovens, still well preserved, which almost entirely occupy the longitudinal layout of the factory. In the external space, some further smaller volumes complete the area together with the chimney still in fair condition today. The construction system is in load-bearing masonry and the building is entirely made of bricks to enhance the product for which the factory was born. Over the centuries, due to the bombings of the Second World War and the reduction in production, many volumes have been destroyed. Currently, in the eyes of ordinary people, the factory looks like a 'cathedral on the sea'. The centrality of the factory in the social life of Scauri is preserved by the locals who still today occupy the square in front with a weekly market, thus guaranteeing, albeit weak, a 'form of life'. The factory is currently owned by the Municipality of Minturno.

\section{Application. Scan to BIM, Smart Cultural Heritage Services and Visitor Experience}

The reuse project of the brick factory has required the application of the DVMR.

In the first phase, the Design (D) of the geographic information system through QGis was fundamental to analyze and understand the territorial context of the site. The GIS, in accordance with the ontological structure of the ISO/TC2I I standards, collected data on three different territorial levels: a) the landscape, with the indication of the vulnerability and consistency of the industrial sites already existing in the territory (in terms of pollution, dimension, renovation, disuse, etc.); b) urban planning, with particular attention to the regulatory but also socio-economic aspects; c) area of the case study, getting of general, dimensional, technological, historical data, etc.

Scan to BIM:Virtual Reality (VR) for the definition of a geometric/parametric model:TheVirtualization (V), in the second phase, performs the procedure known as SCAN to BIM. The size and internal spatial distribution of the plant suggested the use of a digital photogrammetric survey from a drone (returned with the DroneBase XI000 Mapper con fotocamera Sony Alpha ILCE $-600016 \mathrm{mmf} / 7.1$, by double swipe flight plan at a height of $40 \mathrm{~m}$ from the ground) to reproduce the external volume and a laser scan survey (returned with Leika BLK 360 by the scans alignment of a specially designed grid) for the interior. Thanks to the laser scanner survey, the superfetations, the structural consistency and the state of decay of the finishes and structural parts were analyzed. Furthermore, through georeferencing, point clouds can be imported into an $\mathrm{H}-\mathrm{BIM}$ system and the virtual reality model has been built according to the ontological structure of the UNI-I I 337-20 I7 standards (LOD, LOG and LOI). The virtual model of the factory 'Ex Sieci' is characterized by Lod 400/AS BUILT.

Smart heritage services for environmental analysis: Modeling (M) of natural phenomena in virtual environments, in the third phase, is an example of AR technologies. The HBIM parametric model exported, thanks to IFC technology, in a computational fluid dynamics software allows a multi-criteria analysis capable of evaluating the effects of wind on the facades of buildings. The 
model can be imported, in fact, into a virtual wind tunnel, where the average wind direction and intensity are taken from the Annals, and the wind impact on the facades can be virtualized with sized voxels. In addition, taking advantage by geolocation, $\mathrm{H}-\mathrm{BIM}$ performs energy analyses and shows the impact of solar radiation on the facades of buildings during the day. The visualization with false-colour of sunlight on the building walls highlights the surfaces with the greatest exposure to the sun, providing a significant indication in energy efficiency measures. Similarly, it is possible to virtualize in $\mathrm{H}-\mathrm{BIM}$ the execution of different acoustic analysis scenarios, which are of great help in a re-functionalization process. Environmental analysis through Augmented Reality is a very helpful smart heritage service.

Immersive reality (IR) for the intangible cultural heritage:The last phase involves the use of $\mathrm{H}-\mathrm{BIM}$ in the enhancing immaterial value of the place. The design of the ri-function of Hoffmann ovens, very complicated to manage, has combined the IR in two different approaches. One gate of the oven, with interactive screens, holograms and sounds, which recall the seascape in which the factory is located, aims to attract the interest of children to the natural landscape that surrounds the factory; the second gate, narrating the historical events that characterized the factory and the surrounding area during the Second WorldWar, intended to attract the interest of adults.

\section{Conclusion}

The post-industrial heritage, which has marked the cultural and social life of many communities, today requires an impressive process of enhancement that must analyze all the different factors that come into play with a holistic approach. To this end, it is important to define a method that, on the basis of the potential of new technologies, is able to virtualise both the material and immaterial aspects. The method proposed with the abbreviation DVMR was conceived for this purpose and tested on a real case study, the brick factory located in Scauri. This first application, which required the acquisition and processing of many data, both territorial and historical-artistic, will be implemented with additional technologies, $3 \mathrm{D}$ viewers, with the aim of improving the sensitive perception in the enhancement of the intangible cultural value of the site.

\section{References}

Boton Conrad (20I8). Supporting constructability analysis meetings with Immersive Virtual Reality-based collaborative BIM 4D simulation. In Automation in Construction, 96, pp. I- I5.

Delgado Juan Manuel Davila, Oyedele Lukumon, Demian Peter, Beach Thomas (2020). A research agenda for augmented and virtual reality in architecture, engineering and construction. In Advanced Engineering Informatics, 45, I0 I I 22.

Getuli Vito, Capone Pietro, Bruttini Alessandro, Isaac Shabtai (2020). BIM-based immersive Virtual Reality for construction workspace planning: A safety-oriented approach. In Automation in Construction, I I 4, I03 I 60.

Imbimbo Maura, Modoni Giuseppe, Pelliccio Assunta, Saccucci Marco (2019, November). Vulnerability of Buildings: From Heritage Building Information Modelling (HBIM) to Seismic Analysis. In International Conference on Critical Thinking in Sustainable Rehabilitation and Risk Management of the Built Environment. Cham: Springer, pp. 3 I I-329.

Pelliccio Assunta (2020). I luoghi delle industrie dismesse. GIS \& HBIM per la loro valorizzazione/The places of brownfields. GIS \& HBIM for their enhancement. Benevento: Edizioni Efesto.

Pelliccio Assunta, Saccucci Marco, Grande Ernesto (2017). HT_BIM: Parametric modelling for the assessment of risk in historic centers. In DISEGNARECON, IO (I8), pp. 5-II.

Saccucci Marco, Pelliccio Assunta (2018, October). Integrated BIM-GIS system for the enhancement of urban heritage. In 2018 Metrology for Archaeology and Cultural Heritage (MetroArchaeo). Piscataway: IEEE, pp. 222-226.

Wang Jun, Wang Xiangyu, Shou Wenchi, Xu Bo (20I4). Integrating BIM and augmented reality for interactive architectural visualisation. In Construction Innovation, I4 (4), pp. 453-476.

\section{Authors}

Assunta Pelliccio, Dept. of Literature and Philosophy, University of Cassino and Southern Lazio, pelliccio@unicas.it Marco Saccucci, Dept. of Literature and Philosophy, University of Cassino and Southern Lazio, m.saccucci@unicas.it 
